\title{
Targeted Therapies in Sarcomas: Challenging the Challenge
}

\author{
Juan Martín Liberal, ${ }^{1}$ Laura Lagares-Tena, ${ }^{1}$ Miguel Sáinz-Jaspeado, ${ }^{1}$ Silvia Mateo-Lozano, ${ }^{2}$ \\ Xavier García del Muro, ${ }^{1}$ and Oscar M. Tirado ${ }^{1}$ \\ ${ }^{1}$ Laboratori d'Oncología Molecular, Institut d'Investigació Biomèdica de Bellvitge (IDIBELL), \\ L'Hospitalet de Llobregat, 08908 Barcelona, Spain \\ ${ }^{2}$ Nanomedicine Research Program, Molecular Biology and Biochemistry Research Center, CIBBIM-Nanomedicine, \\ Vall d'Hebron Hospital Research Institute, 08035 Barcelona, Spain \\ Correspondence should be addressed to Oscar M. Tirado, omartinez@idibell.cat
}

Received 7 March 2012; Accepted 27 March 2012

Academic Editor: Peter Choong

Copyright ( 2012 Juan Martín Liberal et al. This is an open access article distributed under the Creative Commons Attribution License, which permits unrestricted use, distribution, and reproduction in any medium, provided the original work is properly cited.

Sarcomas are a heterogeneous group of mesenchymal malignancies that very often lead to death. Nowadays, chemotherapy is the only available treatment for most sarcomas but there are few active drugs and clinical results still remain very poor. Thus, there is an imperious need to find new therapeutic alternatives in order to improve sarcoma patient's outcome. During the last years, there have been described a number of new molecular pathways that have allowed us to know more about cancer biology and tumorigenesis. Sarcomas are one of the tumors in which more advances have been made. Identification of specific chromosomal translocations, some important pathways characterization such as mTOR pathway or the insulin-like growth factor pathway, the stunning development in angiogenesis knowledge, and brand new agents like viruses have lead to the development of new therapeutic options with promising results. This paper makes an exhaustive review of preclinical and clinical evidence of the most recent targeted therapies in sarcomas and provides a future view of treatments that may lead to improve prognosis of patients affected with this disease.

\section{Introduction}

Sarcomas are a rare and heterogeneous group of malignant tumors of mesenchymal origin. They can occur through all the lifespan and affect patients of all ages, although certain specific subtypes are more frequent in children and young adults. Almost every part of the body may be involved, bone and soft-tissue being the most typical place of arising. Sarcomas are associated with bad prognosis and approximately $50 \%$ of all patients develop metastases even if they are diagnosed at early stages. Lungs are the most frequent site of dissemination and metastases are the final cause of death in almost all these patients [1]. These high mortality levels make sarcomas one of the most challenging tumors in oncology.

For most sarcomas, chemotherapy is currently the only available treatment. Unfortunately, a very limited number of useful drugs are active against this disease and responses used to be poor and short. In fact, advanced-stage patients treated with the most active drugs in this disease (anthracyclines and ifosfamide) achieve only a median survival of around 1 year [2]. Thus, it is necessary to identify new agents to improve therapy for patients affected by this often mortal condition.

In the last years, great advances have been made in the understanding of sarcomas' molecular biology [3]. Consequently, new targeted compounds have been developed and tested in order to improve efficacy and outcome achieved with classic drugs. This paper will extensively review the most relevant pathways in soft tissue and bone sarcomas and the preclinical and clinical experience with the most recent targeted therapies.

\section{Angiogenesis}

In the last years, angiogenesis has been one of the most studied processes in tumor biology with interesting results. Patients with several malignancies such as renal cancer or 
colorectal cancer are currently being treated with angiogenic inhibitors alone or in combination with conventional chemotherapy. These patients achieve significant improvement in overall survival (OS) and/or progression-free survival (PFS) [4]. Sarcomas have been recently added to the group of tumors in which angiogenesis is known to play an important role.

One of the key effectors in angiogenesis is the vascular endothelial growth factor (VEGF). It is well known that the interaction between VEGF and its receptor 2 (VEGF$\mathrm{R} 2$ ) is the most crucial step in angiogenesis [5-7] and there are some studies that relate VEGF with sarcomas. A study by Potti et al. published in 2004 correlated VEGF serum levels with outcome in patients with sarcoma [8]. 68 out of 273 patients $(24.9 \%)$ included in the study showed VEGF overexpression. The most common sarcomas in which VEGF overexpression was detected were malignant fibrous histiocytoma (30\%), carcinosarcoma (30\%), leiomyosarcoma (25\%), and dermatofibrosarcoma (20\%) but VEGF overexpression had prognostic value only in patients affected with leiomyosarcoma. In addition, this was associated with a shorter survival. Graeven et al. also determined VEGF serum levels in 85 patients with STS before surgery. They found a very strong correlation between tumor grade and VEGF serum levels, the poorest differentiated tumors being the ones with the highest VEGF levels [9]. Another study was designed to assess the correlation between VEGF and tumor grade [10]. Results confirmed that tumor grade correlated with VEGF expression. Furthermore, $78 \%$ of patients who died of sarcoma progression had high VEGF levels. However, VEGF expression was not found to be an independent predictor of OS or disease-free survival (DFS). In contrast, a study by Iyoda et al. that correlated VEGF overexpression and survival in patients with soft-tissue sarcomas (STSs) of the thorax found this correlation statistically significant. Thus, patients with absent or faint VEGF expression had higher 5-year DFS than patients with a strong VEGF expression (83.3\% versus $13.2 \%$, resp.) [11].

Hypoxia-inducible factor $1 \alpha$ (HIF- $1 \alpha$ ) is another important player in angiogenesis since it is a transcription factor that acts as an upstream regulator of VEGF. In a 2006 paper by Shintani et al. HIF- $1 \alpha$ expression was determined by immunohistochemistry in a group of 49 specimens of STS. The analysis showed that patients with a strong or moderate expression of HIF- $1 \alpha$ had poorer OS than those with a weak or negative expression [12].

There are many other angiogenesis markers but not all of them are so clearly related with prognosis and survival as VEGF and HIF- $1 \alpha$ in sarcomas. Microvascular density (MVD) is one of them. Thus, in a work by Comandone et al., patients with high MVD had worse OS and DFS than patients with lower MVD [13]. In contrast, 3 other authors reported results that did not confirm this correlation between MVD and prognosis, so the real role of MVD in sarcomas remains unclear [14-16].

2.1. Angiogenic Inhibitors. These previous data provided a rationale for the development of preclinical and clinical studies with angiogenic inhibitors in sarcomas. An increasing number of these drugs have been developed in the last years and the effects of many of them have been assessed (Figure 1).

2.1.1. Small-Molecule VEGF-R Inhibitors. Sunitinib is a multitargeted tyrosine kinase inhibitor (TKI) active against VEGF-R1, 2, 3, PDGFR and KIT, among others. In 2009, Stacchiotti et al. reported 3 responses and 1 stabilization in a cohort of 5 patients affected with advanced alveolar STS treated with sunitinib [17]. The same year, a phase II trial of sunitinib in the treatment of non-GIST sarcomas was published. A cohort of 53 patients with advanced nonGIST STS received $37.5 \mathrm{mg}$ of sunitinib daily. 10 of these patients (20\%) achieved stable disease (SD) for at least 16 weeks and, interestingly, 1 patient affected with desmoplastic round cell tumor (DSRCT) achieved a durable partial response (PR) for 56 weeks [18]. Focusing on 3 specific histologies (leiomyosarcoma, liposarcoma, and malignant fibrous histiocytoma), a phase II study was reported in 2010. In this trial, 48 patients with unresectable or metastatic STS of the histologies mentioned previously were treated daily with $50 \mathrm{mg}$ of sunitinib malate for 4 weeks every 6 weeks. 3 or less prior lines of therapy were allowed. Median PFS and OS for liposarcoma, leiomyosarcoma, and fibrous histiocytoma were 3.9 and 18.6, 4.2 and 10.1, and 2.5 and 13.6 months, respectively. The 3 -month progression-free rates (PFRs) in the untreated and pretreated patients with liposarcoma, leiomyosarcoma, and fibrous histiocytoma were $75 \%$ and $69.2 \%, 60 \%$, and $62.5 \%$, and $25 \%$ and $44.4 \%$, respectively. The authors concluded that the 3-month PFR of $>40 \%$ suggests activity for sunitinib at least in liposarcomas and leiomyosarcomas [19]. In contrast to these studies, the Gynecologic Oncology Group conducted a phase II study to assess the efficacy of sunitinib in the treatment of recurrent or persistent uterine leiomyosarcoma with disappointing results: of 25 patients enrolled, just 2 achieved a PR and the median PFS was 1.5 months [20].

Sorafenib is another TKI recently added to the group of drugs with activity in sarcomas. This TKI targets VEGF-R 2 and 3, PDGFR, Raf, and KIT, and several preclinical studies have demonstrated efficacy in different soft-tissue and bone sarcoma cell lines [20-25]. These encouraging preclinical results, together with some case reports of responses in patients with sarcomas treated with sorafenib [26, 27], led to the development of several clinical trials. In 2009, Maki et al. published a phase II trial of sorafenib in patients with metastatic or recurrent sarcomas [28]. A total of 145 patients with different types of sarcomas were enrolled but just the angiosarcoma patients met the response rate (RR) primary end point planned for the study (5 out of 37 patients, 14\%). Another study pointed out osteosarcoma as other sarcoma subtype in which sorafenib showed activity. The Italian group conducted a phase II trial of sorafenib in relapsed and unresectable high-grade osteosarcoma after failure of standard therapy that showed 3 PRs (8\%), 2 minor responses (6\%), and 12 SDs (34\%). Furthermore, median PFS and OS were 4 and 7 months, respectively, demonstrating sorafenib as the first targeted therapy active in osteosarcoma [29]. In order to find other responsive histologies to sorafenib, the Southwest Oncology Group (SWOG) promoted a phase II 


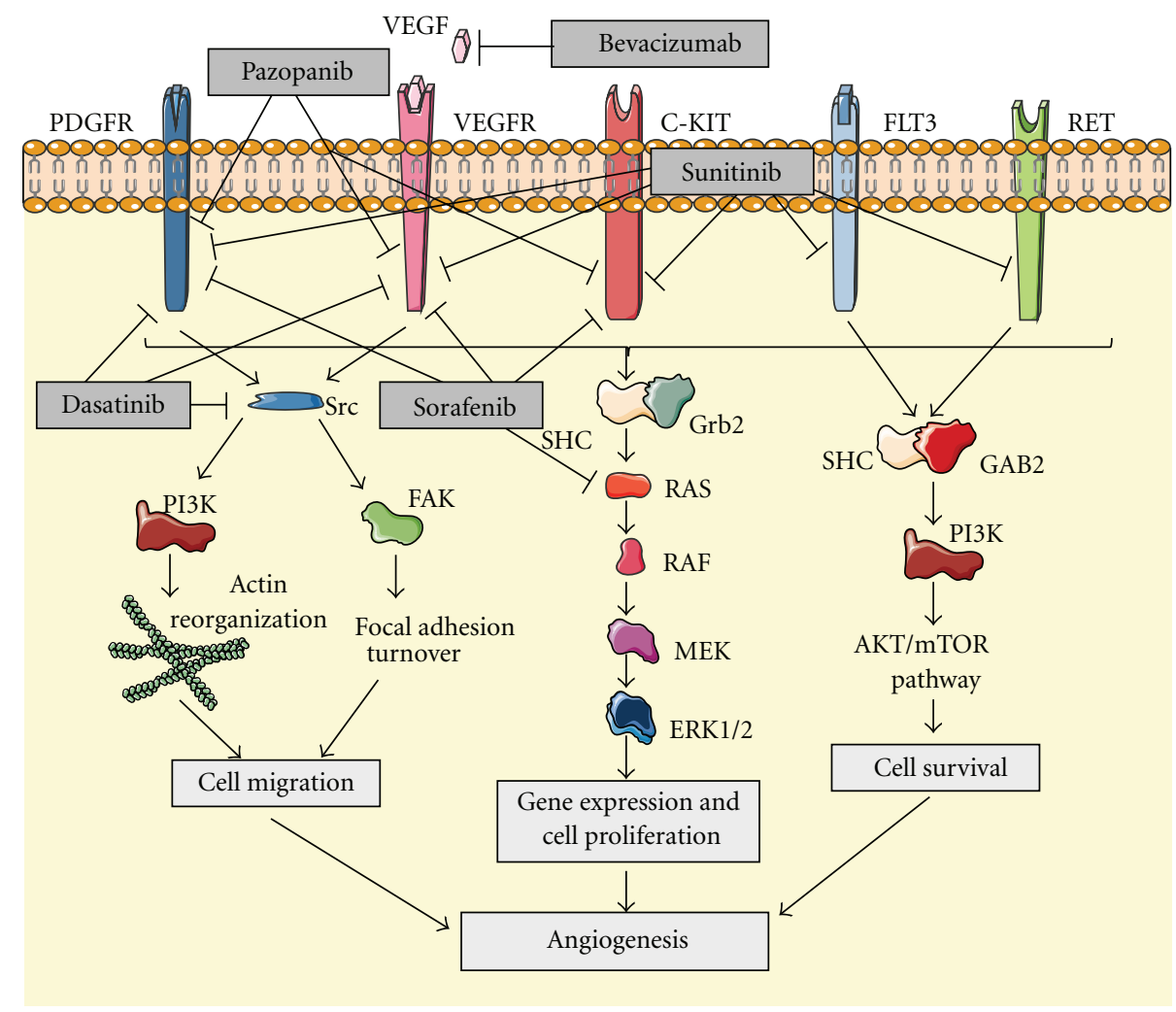

FIGURE 1: Inhibition of angiogenesis by blocking different tumorigenic signaling pathways.

trial testing its activity in advanced vascular sarcoma, highgrade liposarcoma, and leiomyosarcoma [30]. No responses were found and just 6 out of 8 patients with vascular sarcoma achieved clinical benefit. New strategies, such as discontinuation treatment, have also been tested. Thus, Pacey et al. assessed the efficacy of sorafenib in STS in a phase II randomized discontinuation trial [31]. Evidence of activity was found, since some tumor regressions were observed including 1 objective partial response.

Pazopanib is a new TKI that also has effects on angiogenesis by blocking VEGF-R 1, 2, and 3, PDGFR, and KIT. A phase II trial performed by the European Organisation for Research and Treatment of Cancer (EORTC) in patients with relapsed or refractory advanced STS treated with pazopanib achieved promising results [32]. 142 patients were enrolled and they were classified in 4 different groups: adipocytic STS, leiomyosarcomas, synovial sarcomas, and other STS types. Pazopanib in adipocytic STS patients showed insufficient activity but PFR at 12 weeks in the remaining groups was encouraging: 18 (44\%) of 41 patients in the leiomyosarcoma cohort, 18 (49\%) of 37 in the synovial sarcomas, and 16 $(39 \%)$ of 41 in the other STS types. These data led to the first placebo-controlled randomized phase III trial to date with a VEGFR inhibitor (pazopanib) in advanced STS. The results, reported in the 2011 ASCO Annual Meeting, achieved a significant increase in PFS showing the relevance of angiogenesis in sarcomas [33]. Finally, the activity of a new TKI named dasatinib has been assessed in several sarcoma cell lines. This drug blocks VEGF-R2 and PDGFR and has the unique property of inhibiting the Src family. This latter effect leads to the inhibition of migration and invasion in different sarcoma cell lines in vitro, which can lead to further development of clinical trials [34-37].

2.1.2. Anti-VEGF Antibodies. Bevacizumab is the only monoclonal anti-VEGF antibody to date that has been proved to have activity in sarcomas. A set of preclinical studies demonstrated activity in sarcoma models in vitro and in vivo [38-42]. The experience achieved in a number of other malignancies such as colon, breast, or non-small-cell lung cancer, has shown that the effect of bevacizumab in combination with chemotherapy is higher than as a single agent. This strategy was first assessed in sarcomas by D'Adamo el al. in a phase II trial of doxorubicin and bevacizumab in patients with metastatic STS [43]. There were just 2 partial responses but 11 of 17 patients recruited (65\%) achieved stable disease for 4 cycles or more. Interestingly, cardiac toxicity was significantly high and 4 patients developed cardiac toxicity grade 2,1 patient grade 3 , and 1 patient grade 4 despite prophylactic treatment with dexrazoxane. These results suggest the activity of this combination in sarcomas but make necessary finding safer schedules. The efficacy of bevacizumab in combination with other drugs has also been explored in a recently published phase IB trial. In this study, 38 chemotherapy-naive patients with advanced or recurrent STS were treated with a combination of docetaxel, gemcitabine, and bevacizumab [44]. After a median follow-up of 36 months, the overall RR observed was 
31.4\%. There were 5 complete responses (CRs), 6 PRs, and 18 SDs lasting for a median of 6 months. The combination treatment was considered safe and the highest-grade adverse events found were mostly related to bevacizumab.

\section{The Insulin-Like Growth Factor Pathway}

The insulin-like growth factor (IGF) system is a well-known complex network that regulates growth and development in superior organisms (Figure 2). The IGF receptor type 1 (IGFR-1) belongs to the family of tyrosine kinase receptors. The binding of its ligand IGF1 causes its phosphorylation and the subsequent activation of the downstream pathway that finally leads to proliferation and inhibition of apoptosis. The relationship between the IGF system and sarcomas is long-time known but the first studies to describe it were merely epidemiological [45]. In the last years, a variety of studies have confirmed this point. Thus, Prieur et al. described in 2004 the binding of EWS/FLI1 to the IGFBP3 promoter and the subsequent inhibition of IGFBP3 and the increase in free IGFR-1 ligand levels, which are related to the development of this malignancy [46]. Other sarcomas such as alveolar soft part sarcoma, leiomyosarcoma, synovial sarcoma, rhabdomyosarcoma, or desmoplastic small round cell tumor have also been described as tumors in which increases in IGFR-1 levels or some of its ligands have been correlated with sarcomagenesis [47-58].

3.1. IGF Pathway Inhibitors. The background described previously has led to the development of several studies that test different strategies to assess the inhibition of the IGF pathway in sarcoma models in vitro and in vivo [59-67]. The results, especially in rhabdomyosarcoma and Ewing's sarcoma, have been encouraging and the clinical development of these drugs is currently being carried out.

3.1.1. Anti-IGFR-1 Antibodies. Among the different strategies developed to inhibit the IGF pathway, the most promising results have been achieved with monoclonal antibodies. There are several phase I studies that assess the safety and efficacy of inhibiting the IGF system in sarcomas with these drugs. Thus, Tolcher et al. published in 2009 an early clinical study with AMG 479, a fully human monoclonal antibody to IGFR-1. 15 out of 53 patients enrolled were sarcoma patients (12 Ewing's sarcoma, 3 others). Interestingly, 1 durable CR and $1 \mathrm{PR}$ were achieved in 2 patients with Ewing's sarcoma [68]. In another phase I study recently published, a cohort of patients with different sarcoma histologies were treated with figitumumab (a fully human monoclonal antibody targeting the IGFR-1). Among 29 patients enrolled, 2 Ewing's sarcoma patients had objective responses ( $1 \mathrm{CR}, 1 \mathrm{PR}), 6$ Ewing's sarcoma patients, 1 synovial sarcoma, and 1 fibrosarcoma achieved SD [69]. Unfortunately, the clinical development of this drug has been stopped due to disappointing results in other malignancies.

Several phase II trials with anti-IGFR-1 antibodies are currently being conducted. Preliminary data of treatment with IMC-A12 (cixutumumab) in patients with advanced or metastatic STS and Ewing's sarcoma have been reported in the 2011 ASCO Annual Meeting. The best results were observed in the adipocytic sarcoma arm, with clinical benefit being achieved in 22 out of 37 patients (1 PR, 21 SD). Moreover, the PFS at 12 weeks in this group of patients was $50 \%$ [70]. With such promising results, further investigations are warranted.

3.1.2. IGFR-1 TKIs. A number of small molecules that inhibit IGFR-1 by binding to the tyrosine kinase intracellular portion of the receptor are currently in clinical development. No results of efficacy and safety are available yet but there is a body of preclinical data that support this therapeutic approach [71-78]. Reports of clinical outcome in patients treated with these drugs are long awaited and will allow us to confirm the usefulness of this strategy.

\section{The Mammalian Target Rapamycin Pathway}

The mammalian target of rapamycin (mTOR) is a serine/threonine kinase integrated in the phosphatidyl-inositol 3-kinase (PI3K) complex network of signaling. It forms part of 2 multiprotein complexes named mTOR complex 1 and mTOR complex 2 (mTORC1 and mTORC2) and plays a key role in cell growth, proliferation, angiogenesis, and survival (Figure 3). Due to the many functions that mTOR regulates, its abnormal activity leads to a number of malignancies including sarcomas. The upregulation of growth factors or mutations in tyrosine kinase receptors that belongs to the mTOR network have been reported to be involved in the development of various sarcomas [79-84]. Furthermore, deletions of some mTOR pathway tumor suppressors such as tuberous sclerosis complex 1 and 2 (TSC1 and TSC2) and neurofibromatosis type 1 (NF1) are associated with both, benign and malignant mesenchymal tumors [85-88]. Hence, the capital importance of mTOR in tumorigenesis has made the development of mTOR inhibitors an important issue in oncology.

4.1. mTOR Inhibitors. To date, 4 compounds with antimTOR activity have reached the clinical setting. All of them belong to a single family of drugs and are derived from an initial molecule called sirolimus (rapamycin). Thus, temsirolimus, everolimus, ridaforolimus, and the already mentioned sirolimus are nowadays under investigation in sarcomas and other tumors. Sirolimus inhibits mTOR kinase activity by binding to FK506 binding protein (FKBP12), one of the proteins that form mTORC1. This leads to cell cycle arresting in G1 phase and the subsequent inhibition in proliferation and cell growth. Preclinical data suggest activity of sirolimus in some paediatric malignancies including Ewing's sarcoma, rhabdomyosarcoma, and osteosarcoma $[89,90]$. But, despite preclinical evidences, the only phase II trial with sirolimus in sarcomas to date (combined with ciclofosfamide) has been reported as negative [91]. A prodrug of sirolimus named temsirolimus has also been tested in treatment of sarcoma. At least 2 papers have reported tumor growth inhibition in murine xenograft models of 


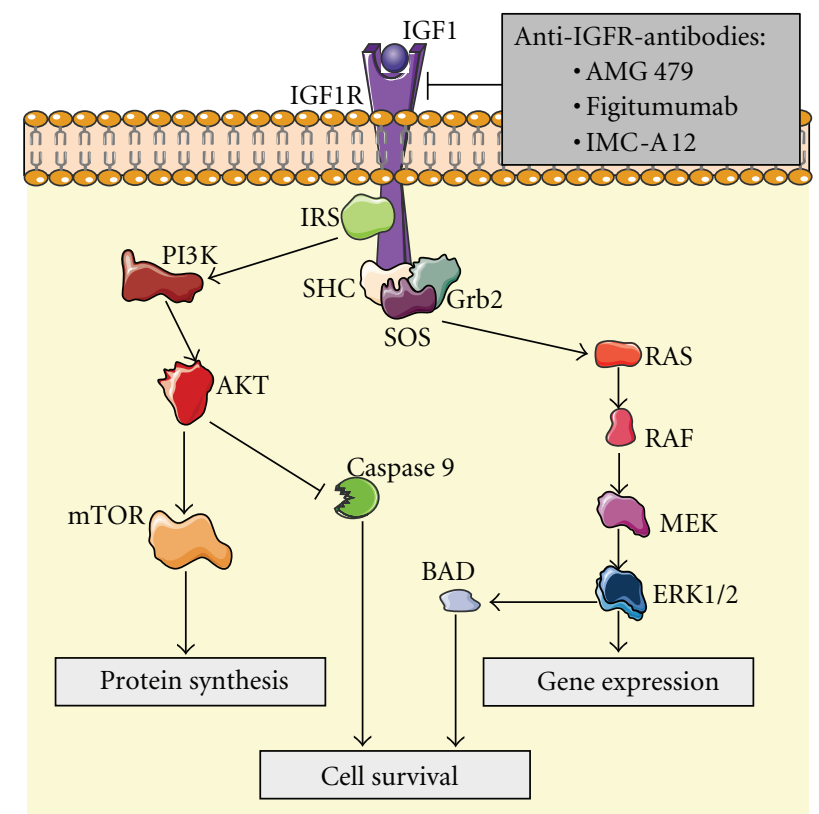

FIGURE 2: The activation of IGFR by ligand binding triggers a signal transduction pathway that causes the activation of mTOR pathway and inhibition of apoptosis, thus promoting cell survival. Anti-IGFR antibodies prevent this effect.

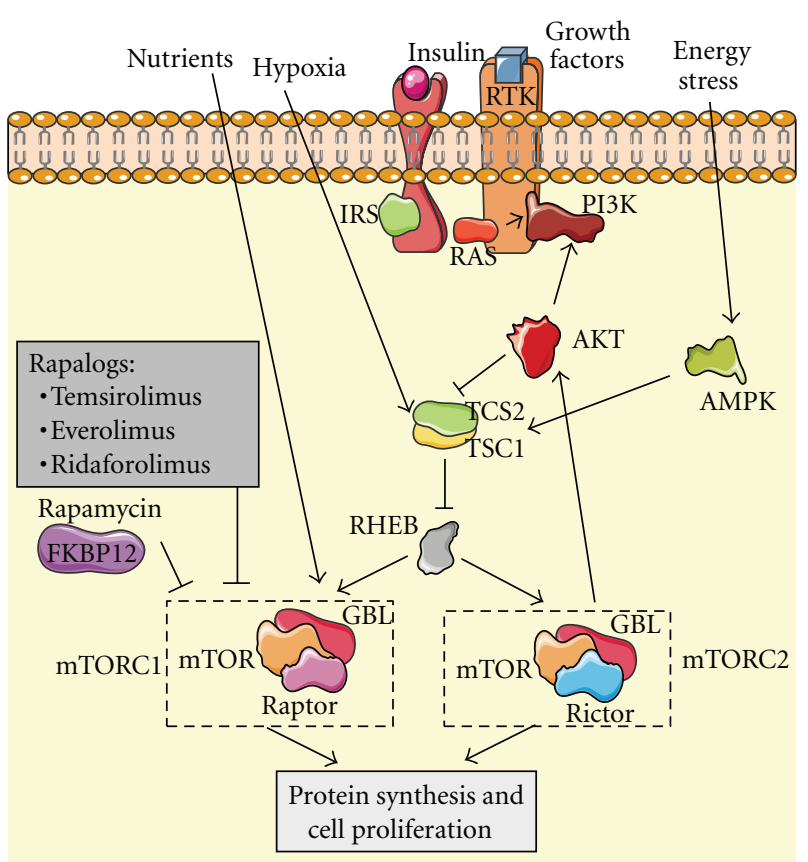

FIGURE 3: AKT activation, among other stimulus, can activate mTOR complexes, mTORC1 and mTORC2, promoting protein synthesis and cell proliferation. Rapamycin and rapalogs are specific inhibitors of mTORC1 but an escape route remains through mTORC2 activity.

rhabdomyosarcoma when treated with temsirolimus [92, 93]. But the first phase II trial published reported disappointing results, with just 2 out of 41 STS patients achieving PR. Thus, the authors concluded that temsirolimus in patients with STS has limited clinical activity and significant toxicity [94]. On the other hand, preliminary results of another phase II trial of temsirolimus in pediatric patients with neuroblastoma, high-grade glioma, and rhabdomyosarcoma are slightly more encouraging, with 2 PR (1 neuroblastoma, 1 rhabdomyosarcoma) and 11 SD from a total of 52 patients [95]. Everolimus is an orally available mTOR inhibitor developed to be much more soluble than sirolimus. Cell cycle arrest in different tumor models has been observed with everolimus and even prolonged survival in a murine 
model of leiomyosarcoma has been reported [96]. The only preliminary data reported to date of a phase II trial of everolimus in STS or bone sarcoma showed a clinical efficacy (CR + PR + SD) of 20\% [97]. The last member of the family of rapamycin analogs (also called rapalogs) is ridaforolimus. It has a better pharmacokinetic profile, presenting a more favorable bioavailability than sirolimus. Activity of ridaforolimus alone has been confirmed in cell lines and xenograft models of sarcoma. Moreover, additive inhibitory effects when combined with cytotoxic agents have also been reported [98]. In the clinical setting, a phase II trial by Chawla et al. achieved a $29 \%$ clinical benefit in patients with advanced sarcoma treated with intravenous ridaforolimus and a median OS of 40 weeks [99]. Such interesting results led to the only phase III trial to date with an mTOR inhibitor: the SUCCEED trial. This double-blind, placebo-controlled phase III trial randomized sarcoma patients who had achieved CR, PR, or SD after 1,2 , or 3 lines of chemotherapy to receive placebo or ridaforolimus as maintenance treatment. Results recently reported showed a $28 \%$ reduction in the risk of progression in ridaforolimus arm compared with placebo arm and a 3.1-week improvement in PFS [100]. Mature OS data are not yet available but everything indicates that ridaforolimus is a promising drug in treatment of sarcomas and further investigations are warranted.

A very rare type of mesenchymal malignant tumor named Perivascular Epithelioid Cell Tumor (PEComa) has been specially related to the mTOR pathway. Dysfunction in tumor suppressors TSC1 and 2 and the subsequent upregulation of mTORC1 seems to be a crucial step in the development of this disease. Thus, responses with sirolimus and temosirolimus have been reported in at least 2 studies [101, 102]. However, another study did not find these positive results, making necessary additional investigations [103].

All 4 rapalogs described previously belong to a first generation of mTOR inhibitors able to inhibit mTORC1 but not mTORC2. mTORC2 seems to be responsible for feedback phosphorylation of Akt in the PI3K/Akt pathway, which could be a possible mechanism of resistance in sarcomas. So, a new generation of mTOR inhibitors with activity against mTORC1 and mTORC2 is under early development in an attempt to block this escape route.

\section{Specific Chromosomal Translocations as Therapeutic Targets}

About 1/3 of sarcomas are associated with specific chromosomal translocations. These translocations are an early step in carcinogenesis, promoting some of the processes that finally lead to the appearance of sarcomas [104]. Thus, trying to inhibit the effects of these genetic alterations seems to be a reasonable option in fighting sarcomas. Dermatofibrosarcoma protuberans is an example of this group of sarcomas. It is characterized by a $t(17 ; 22)$ translocation that leads to the overexpression of platelet-derived growth factor B (PDGFB). Imatinib is a TKI with known activity against the receptor of PDGFB, PDGFR. Because of that, its efficacy has been assessed in dermatofibrosarcoma protuberans with excellent results (46\% PR, 25\% SD) $[105,106]$.

Clear cell sarcoma is also associated with a specific chromosomal translocation, $\mathrm{t}(12 ; 22)(\mathrm{q} 13 ; \mathrm{q} 12)$ in most of the cases. One of the consequences of this chromosomal rearrangement is the activation of the hepatocyte growth factor receptor (MET). This activation is involved in invasion and angiogenesis. A response in a clear cell sarcoma patient with the MET inhibitor ARQ197 has recently been reported in a phase II trial, which is especially relevant in this treatment-resistant disease [107].

But probably the most studied translocation-related sarcoma is Ewing's sarcoma. This disease characteristically has a $t(11 ; 22)$ translocation that leads to expression of the oncogenic fusion protein EWS/FLI1. This chimerical protein is involved in Ewing's sarcoma development since it acts as an oncogenic transcription factor but needs binding to other proteins such as RNA helicase A for its oncogenic function. Recently described YK-4-279, a new compound that blocks RNA helicase A binding to EWS/FLI1, induces apoptosis in Ewing's sarcoma cell lines and reduces tumor growth in orthotopic xenografts [108]. A clinical trial to assess the efficacy of this new drug is planned.

\section{Virotherapy}

One of the most innovative approaches in cancer treatment developed in the last years is oncolytic virotherapy. The general basis of this strategy is that the therapeutic virus is capable to recognize specifically tumor cells, replicate into them, and lead to their death without damaging normal cells. A paper recently published in Nature by Breitbach et al. assessed the safety and efficacy of an intravenous delivery of an oncolytic poxvirus in humans. Treatment was generally well tolerated and the only sarcoma patient enrolled (a 55-year-old female with a heavily pretreated advanced leiomyosarcoma) achieved SD by RECIST criteria for $>16$ weeks [109]. This result is as encouraging for sarcoma treatment as a 2010 study published by Li et al. In that paper, the authors reported marked cytolysis and apoptosis in osteosarcoma cell lines in vitro and significant tumor growth suppression in a human osteosarcoma murine xenograft model when treated with a telomerase-specific oncolytic adenovirus [110]. More in-deep preclinical and clinical investigations are needed but virotherapy seems a feasible and reasonable option in future treatments for sarcomas.

\section{Combined Targeted Therapies}

Although clinical experience with targeted therapies in sarcomas as single treatment is short, there are some published studies with combination of 2 of these drugs. The most studied double-inhibition-targeted therapies are those related with IGFR-1 pathway, with preclinical evidences of activity in sarcoma models [111-113]. Based on these studies, at least 2 phase I trials have been reported, one 


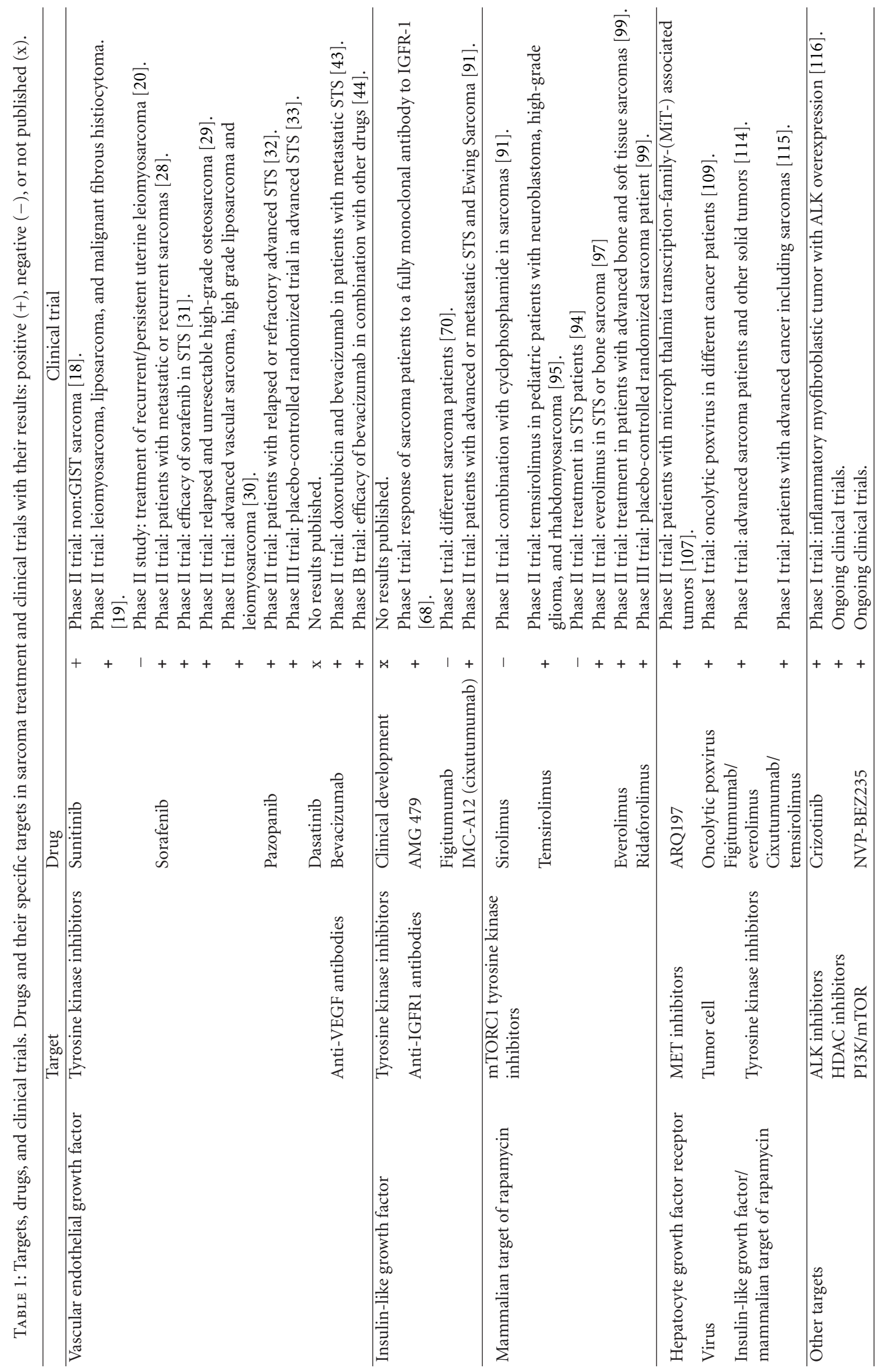


of them with figitumumab and everolimus in advanced sarcoma patients and the other solid tumors and the other with cixutumumab combined with temsirolimus in Ewing's sarcoma patients that is currently enrolling [114, 115]. Both studies reported good toxicity profiles, making the combination of 2 targeted therapies an attractive and safe option to be developed. Most trials involving the targeted therapies reviewed in this paper are summarized in Table 1.

\section{Future Perspectives}

An increasing number of new targets in treatment of sarcomas are being identified in the last years. The finding of new important key effectors in sarcomas biology has resulted in a growing development of inhibitor drugs that need to be tested. For instance, increased activity in Hedgehog pathway has recently been reported in certain sarcomas such as rhabdomyosarcoma, osteosarcoma, chondrosarcoma, and Ewing's sarcoma [117-121]. Other reports suggest that rhabdomyosarcoma and osteosarcoma aggressiveness seems to be related with Notch signalling pathway $[122,123]$. This has led to the conduction of a clinical trial with Hedgehog and Notch inhibitors with no results to date.

Anaplastic lymphoma kinase (ALK) is another protein recently related to sarcomas that is upregulated in approximately $50 \%$ of cases of inflammatory myofibroblastic tumor. Interestingly, in a phase I trial with the ALK inhibitor crizotinib, a patient with ALK overexpression related to inflammatory myofibroblastic tumor experienced a durable PR [116].

Histone deacetylase (HDAC) inhibitors have also shown signs of efficacy in preclinical models of sarcomas [124-128] and several clinical trials are currently ongoing.

$\mathrm{PI} 3 \mathrm{~K} / \mathrm{mTOR}$ dual-inhibitor NVP-BEZ235 that induces G1 cell cycle arrest in sarcomas in vitro and in vivo [129] has been identified as well as a brand new promising agent.

Other molecules such as MDM2 and protein families BCL-2 and CDKs have been described lately as associated with sarcomas [130-132]. Future investigations with inhibitors are warranted.

\section{Conclusions}

Despite the low incidence of sarcomas in general population regarding other types of cancer, the finding of new active treatments is essential since it is a rarely curable disease. Hence, a rapidly increasing number of targeted therapies have been developed in the last years with different results. In general, most of these treatments do not achieve significant tumor shrinkage and SD is usually the best response reported. In addition, OS has not been dramatically increased in the majority of these patients, showing the necessity of keep working. In an attempt to improve response rates, one of the strategies that are currently ongoing is the combination treatment with targeted therapies and conventional cytotoxic drugs. Toxicity is an important issue when using this approach and more clinical trials are needed to assess the safety of this therapeutic option. Combinations of more than one targeted agent are another reasonable choice. The strategy of inhibiting a signalling pathway and simultaneously others that could be possible ways of escape is an attractive alternative still under early development. Phase I trials reported to date with 2 targeted therapies show favourable toxicity profiles, making this strategy a feasible and promising issue to be explored. Different approaches like those, future identification of new pathways and their correspondent inhibitors and the arise of innovative agents such as oncolytic viruses, make the final endpoint of cure sarcsomas a goal not so far to be reached.

\section{Acknowledgments}

L. Lagares-Tena is funded by the Comissionat per a Universitats i Recerca (CUR) from Departament d'Innovació, Universitats i Empresa (DIUE) de la Generalitat de Catalunya i del Fons Social Europeu. Figures were produced using Servier Medical Art. The work in the Sarcoma Research Group is supported by grants from the Fondo de Investigaciones Sanitarias-ISCIII (CP06/00151; PI08/0259; PI11/00038) and from the Ministerio de sanidad y Consumo (TRA-163).

\section{References}

[1] A. Italiano, S. Mathoulin-Pelissier, A. Le Cesne et al., "Trends in survival for patients with metastatic soft-tissue sarcoma," Cancer, vol. 117, no. 5, pp. 1049-1054, 2011.

[2] P. G. Casali and J. Y. Blay, "ESMO/CONTICANET/ EUROBONET Consensus Panel of experts. Soft tissue sarcomas: ESMO Clinical Practice Guidelines for diagnosis, treatment and follow-up," Annals of Oncology, vol. 21, supplement 5, pp. v198-v203, 2010.

[3] E. Wardelmann, H. U. Schildhaus, S. Merkelbach-Bruse et al., "Soft tissue sarcoma: from molecular diagnosis to selection of treatment. Pathological diagnosis of soft tissue sarcoma amid molecular biology and targeted therapies," Annals of Oncology, vol. 21, no. 7, pp. vii265-vii269, 2010.

[4] R. K. Jain, D. G. Duda, J. W. Clark, and J. S. Loeffler, "Lessons from phase III clinical trials on anti-VEGF therapy for cancer," Nature Clinical Practice Oncology, vol. 3, no. 1, pp. 24-40, 2006.

[5] N. Ferrara, "Vascular endothelial growth factor: basic science and clinical progress," Endocrine Reviews, vol. 25, no. 4, pp. 581-611, 2004.

[6] N. Ferrara, "VEGF-A: a critical regulator of blood vessel growth," European Cytokine Network, vol. 20, no. 4, pp. 158163, 2009.

[7] J. A. Nagy, A. M. Dvorak, and H. F. Dvorak, "VEGF-A and the induction of pathological angiogenesis," Annual Review of Pathology, vol. 2, pp. 251-275, 2007.

[8] A. Potti, A. K. Ganti, K. Tendulkar et al., "Determination of vascular endothelial growth factor (VEGF) overexpression in soft tissue sarcomas and the role of overexpression in leiomyosarcoma," Journal of Cancer Research and Clinical Oncology, vol. 130, no. 1, pp. 52-56, 2004.

[9] U. Graeven, N. Andre, E. Achilles, C. Zornig, and W. Schmiegel, "Serum levels of vascular endothelial growth factor and basic fibroblast growth factor in patients with soft-tissue sarcoma," Journal of Cancer Research and Clinical Oncology, vol. 125, no. 10, pp. 577-581, 1999. 
[10] C. Chao, T. Al-Saleem, J. J. Brooks, A. Rogatko, W. G. Kraybill, and B. Eisenberg, "Vascular endothelial growth factor and soft tissue sarcomas: tumor expression correlates with grade," Annals of Surgical Oncology, vol. 8, no. 3, pp. 260-267, 2001.

[11] A. Iyoda, K. Hiroshima, M. Baba, T. Fujisawa, T. Yusa, and H. Ohwada, "Expression of vascular endothelial growth factor in thoracic sarcomas," Annals of Thoracic Surgery, vol. 71, no. 5, pp. 1635-1639, 2001.

[12] K. Shintani, A. Matsumine, K. Kusuzaki et al., "Expression of hypoxia-inducible factor (HIF)- $1 \alpha$ as a biomarker of outcome in soft-tissue sarcomas," Virchows Archiv, vol. 449, no. 6, pp. 673-681, 2006.

[13] A. Comandone, A. Boglione, E. Berardengo et al., "Microvessel density (MVD) as a marker of neoangiogenesis: prognostic significance in correlation to grading and stage in adult soft tissue sarcoma (STS) of the extremities. A perspective study," Proceedings of the American Society of Clinical Oncology, vol. 22, abstract 3303, 2003.

[14] C. C. West, N. J. Brown, D. C. Mangham, R. J. Grimer, and M. W. R. Reed, "Microvessel density does not predict outcome in high grade soft tissue sarcoma," European Journal of Surgical Oncology, vol. 31, no. 10, pp. 1198-1205, 2005.

[15] N. C. Saenz, M. J. Heslin, V. Adsay et al., "Neovascularity and clinical outcome in high-grade extremity soft tissue sarcomas," Annals of Surgical Oncology, vol. 5, no. 1, pp. 4853,1998

[16] K. Yudoh, M. Kanamori, K. Ohmori, T. Yasuda, M. Aoki, and T. Kimura, "Concentration of vascular endothelial growth factor in the tumour tissue as a prognostic factor of soft tissue sarcomas," British Journal of Cancer, vol. 84, no. 12, pp. 1610 1615, 2001.

[17] S. Stacchiotti, E. Tamborini, A. Marrari et al., "Response to sunitinib malate in advanced alveolar soft part sarcoma," Clinical Cancer Research, vol. 15, no. 3, pp. 1096-1104, 2009.

[18] S. George, P. Merriam, R. G. Maki et al., "Multicenter phase II trial of sunitinib in the treatment of nongastrointestinal stromal tumor sarcomas," Journal of Clinical Oncology, vol. 27, no. 19, pp. 3154-3160, 2009.

[19] S. T. Mahmood, S. Agresta, C. Vigil et al., "Phase II study of sunitinib malate, a multi-targeted tyrosine kinase inhibitor in patients with relapsed or refractory soft tissue sarcomas. Focus on 3 prevalent histologies: Leiomyosarcoma, liposarcoma, and malignant fibrous histiocytoma," International Journal of Cancer, vol. 129, pp. 1963-1969, 2010.

[20] M. L. Hensley, M. W. Sill, D. R. Scribner et al., "Sunitinib malate in the treatment of recurrent or persistent uterine leiomyosarcoma: a Gynecologic Oncology Group phase II study," Gynecologic Oncology, vol. 115, no. 3, pp. 460-465, 2009.

[21] X. Lu, X. Tang, W. Guo, T. Ren, and H. Zhao, "Sorafenib induces growth inhibition and apoptosis of human chondrosarcoma cells by blocking the RAF/ERK/MEK pathway," Journal of Surgical Oncology, vol. 102, no. 7, pp. 821-826, 2010.

[22] Y. Pignochino, G. Grignani, G. Cavalloni et al., "Sorafenib blocks tumour growth, angiogenesis and metastatic potential in preclinical models of osteosarcoma through a mechanism potentially involving the inhibition of ERK1/2, MCL-1 and ezrin pathways," Molecular Cancer, vol. 8, article 118, 2009.

[23] W. Maruwge, P. D’Arcy, A. Folin et al., "Sorafenib inhibits tumor growth and vascularization of rhabdomyosarcoma cells by blocking IGF-1R-mediated signaling," OncoTargets and Therapy, vol. 1, pp. 67-78, 2008.
[24] C. L. Peng, W. Guo, T. Ji et al., "Sorafenib induces growth inhibition and apoptosis in human synovial sarcoma cells via inhibiting the RAF/MEK/ERK signaling pathway," Cancer Biology and Therapy, vol. 8, no. 18, pp. 1729-1736, 2009.

[25] G. Ambrosini, H. S. Cheema, S. Seelman et al., "Sorafenib inhibits growth and mitogen-activated protein kinase signaling in malignant peripheral nerve sheath cells," Molecular Cancer Therapeutics, vol. 7, no. 4, pp. 890-896, 2008.

[26] A. Ardavanis, D. Doufexis, P. Kountourakis, and G. Rigatos, "A Kaposi's sarcoma complete clinical response after sorafenib administration," Annals of Oncology, vol. 19, no. 9, pp. 1658-1659, 2008.

[27] U. Basso, A. Brunello, A. Bertuzzi, and A. Santoro, "Sorafenib is active on lung metastases from synovial sarcoma," Annals of Oncology, vol. 20, no. 2, pp. 386-387, 2009.

[28] R. G. Maki, D. R. D'Adamo, M. L. Keohan et al., "Phase II study of sorafenib in patients with metastatic or recurrent sarcomas," Journal of Clinical Oncology, vol. 27, no. 19, pp. 3133-3140, 2009.

[29] G. Grignani, E. Palmerini, P. Dileo et al., "A phase II trial of sorafenib in relapsed and unresectable high-grade osteosarcoma after failure of standard multimodal therapy: an ItalianSarcoma Group study," Annals of Oncology, vol. 23, pp. 508-516, 2012.

[30] M. Von Mehren, C. Rankin, J. R. Goldblum et al., "Phase 2 Southwest Oncology Group-directed intergroup trial (S0505) of sorafenib in advanced soft tissue sarcomas," Cancer, vol. 118, pp. 770-776, 2012.

[31] S. Pacey, M. J. Ratain, K. T. Flaherty et al., "Efficacy and safety of sorafenib in a subset of patients with advanced soft tissue sarcoma from a phase II randomized discontinuation trial," Investigational New Drugs, vol. 29, no. 3, pp. 481-488, 2011.

[32] S. Sleijfer, I. Ray-Coquard, Z. Papai et al., "Pazopanib, a multikinase angiogenesis inhibitor, in patients with relapsed or refractory advanced soft tissue sarcoma: a phase II study from the European organisation for research and treatment of cancer-soft tissue and bone sarcoma group (EORTC Study 62043)," Journal of Clinical Oncology, vol. 27, no. 19, pp. 3126-3132, 2009.

[33] W Van-der-Graaf, J. Blay, S. P. Chawla et al., "PALETTE: a randomized, double-blind, phase III trial of pazopanib versus placebo in patients (pts) with soft-tissue sarcoma (STS) whose disease has progressed during or following prior chemotherapy-an EORTC STBSG Global Network Study (EORTC 62072)," Journal of Clinical Oncology, vol. 29, abstract LBA10002, 2011.

[34] A. C. Shor, E. A. Keschman, F. Y. Lee et al., "Dasatinib inhibits migration and invasion in diverse human sarcoma cell lines and induces apoptosis in bone sarcoma cells dependent on Src kinase for survival," Cancer Research, vol. 67, no. 6, pp. 2800-2808, 2007.

[35] F. Timeus, N. Crescenzio, A. Fandi, A. Doria, L. Foglia, and L. C. di Montezemolo, "In vitro antiproliferative and antimigratory activity of dasatinib in neuroblastoma and Ewing sarcoma cell lines," Oncology Reports, vol. 19, no. 2, pp. 353-359, 2008.

[36] P. Hingorani, W. Zhang, R. Gorlick, and E. A. Kolb, "Inhibition of Src phosphorylation alters metastatic potential of osteosarcoma in vitro but not in vivo," Clinical Cancer Research, vol. 15, no. 10, pp. 3416-3422, 2009.

[37] Y. M. Schrage, I. H. Briaire-de Bruijn, N. F. C. C. De Miranda et al., "Kinome profiling of chondrosarcoma reveals Srcpathway activity and dasatinib as option for treatment," Cancer Research, vol. 69, no. 15, pp. 6216-6222, 2009. 
[38] S. Dalal, A. M. Berry, C. J. Cullinane et al., "Vascular endothelial growth factor: a therapeutic target for tumors of the Ewing's sarcoma Family," Clinical Cancer Research, vol. 11, no. 6, pp. 2364-2378, 2005.

[39] A. Ferrario and C. J. Gomer, "Avastin enhances photodynamic therapy treatment of Kaposi's sarcoma in a mouse tumor model," Journal of Environmental Pathology, Toxicology and Oncology, vol. 25, pp. 251-259, 2006.

[40] D. T. Vistica, M. Hollingshead, S. D. Borgel et al., "Therapeutic vulnerability of an in vivo model of alveolar soft part sarcoma (ASPS) to antiangiogenic therapy," Journal of Pediatric Hematology/Oncology, vol. 31, no. 8, pp. 561-570, 2009.

[41] A. L. Myers, R. F. Williams, C. Y. Ng, J. E. Hartwich, and A. M. Davidoff, "Bevacizumab-induced tumor vessel remodeling in rhabdomyosarcoma xenografts increases the effectiveness of adjuvant ionizing radiation," Journal of Pediatric Surgery, vol. 45 , no. 6, pp. 1080-1085, 2010.

[42] Y. Okada, T. Akisue, H. Hara et al., "The effect of bevacizumab on tumour growth of malignant fibrous histiocytoma in an animal model," Anticancer Research, vol. 30, no. 9, pp. 3391-3395, 2010.

[43] D. R. D’Adamo, S. E. Anderson, K. Albritton et al., "Phase II study of doxorubicin and bevacizumab for patients with metastatic soft-tissue sarcomas," Journal of Clinical Oncology, vol. 23, no. 28, pp. 7135-7142, 2005.

[44] C. F. Verschraegen, H. Arias-Pulido, S. J. Lee et al., "Phase IB study of the combination of docetaxel, gemcitabine, and bevacizumab in patients with advanced or recurrent soft tissue sarcoma: the Axtell regimen," Annals of Oncology, vol. 23, pp. 785-790, 2011.

[45] R. Gorlick, P. Anderson, I. Andrulis et al., "Biology of childhood osteogenic sarcoma and potential targets for therapeutic development: Meeting Summary," Clinical Cancer Research, vol. 9, no. 15, pp. 5442-5453, 2003.

[46] A. Prieur, F. Tirode, P. Cohen, and O. Delattre, "EWS/FLI-1 silencing and gene profiling of Ewing cells reveal downstream oncogenic pathways and a crucial role for repression of insulin-like growth factor binding protein 3," Molecular and Cellular Biology, vol. 24, no. 16, pp. 7275-7283, 2004.

[47] J. Khan, M. L. Bittner, L. H. Saal et al., "cDNA microarrays detect activation of a myogenic transcription program by the PAX3-FKHR fusion oncogene," Proceedings of the National Academy of Sciences of the United States of America, vol. 96, no. 23, pp. 13264-13269, 1999.

[48] D. Ayalon, T. Glaser, and H. Werner, "Transcriptional regulation of IGF-I receptor gene expression by the PAX3FKHR oncoprotein," Growth Hormone and IGF Research, vol. 11, no. 5, pp. 289-297, 2001.

[49] E. Karnieli, H. Werner, F. J. Rauscher, L. E. Benjamin, and D. Leroith, "The IGF-I receptor gene promoter is a molecular target for the Ewing's sarcoma-Wilms' tumor 1 fusion protein," Journal of Biological Chemistry, vol. 271, no. 32, pp. 19304-19309, 1996.

[50] I. Finkeltov, S. Kuhn, T. Glaser et al., "Transcriptional regulation of IGF-I receptor gene expression by novel isoforms of the EWS-WT1 fusion protein," Oncogene, vol. 21, no. 12, pp. 1890-1898, 2002.

[51] H. Werner, G. Idelman, M. Rubinstein, P. Pattee, S. R. Nagalla, and C. T. Roberts, "A novel EWS-WT1 gene fusion product in desmoplastic small round cell tumor is a potent transactivator of the insulin-like growth factor-I receptor (IGF-IR) gene," Cancer Letters, vol. 247, no. 1-2, pp. 84-90, 2007.
[52] P. V. Pedone, R. Tirabosco, A. O. Cavazzana et al., "Monoand bi-allelic expression of insulin-like growth factor II gene in human muscle tumors," Human Molecular Genetics, vol. 3, no. 7, pp. 1117-1121, 1994.

[53] H. Scrable, W. Cavenee, F. Ghavimi, M. Lovell, K. Morgan, and C. Sapienza, "A model for embryonal rhabdomyosarcoma tumorigenesis that involves genome imprinting," Proceedings of the National Academy of Sciences of the United States of America, vol. 86, no. 19, pp. 7480-7484, 1989.

[54] M. Visser, C. Sijmons, J. Bras et al., "Allelotype of pediatric rhabdomyosarcoma," Oncogene, vol. 15, no. 11, pp. 13091314, 1997.

[55] S. Zhan, D. N. Shapiro, and L. J. Helman, "Activation of an imprinted allele of the insulin-like growth factor II gene implicated in rhabdomyosarcoma," Journal of Clinical Investigation, vol. 94, no. 1, pp. 445-448, 1994.

[56] J. Anderson, A. Gordon, K. Pritchard-Jones et al., "Genes, chromosomes, and rhabdomyosarcoma," Genes Chromosomes Cancer, vol. 26, pp. 275-285, 1999.

[57] Y. Sun, D. Gao, Y. Liu, J. Huang, S. Lessnick, and S. Tanaka, "IGF2 is critical for tumorigenesis by synovial sarcoma oncoprotein SYT-SSX1," Oncogene, vol. 25, no. 7, pp. 10421052, 2006.

[58] D. R. H. De Bruijn, S. V. Allander, A. H. A. Van Dijk et al., "The synovial sarcoma-associated SS18-SSX2 fusion protein induces epigenetic gene (de)regulation," Cancer Research, vol. 66, no. 19, pp. 9474-9482, 2006.

[59] D. N. Shapiro, B. G. Jones, L. H. Shapiro, P. Dias, and P. J. Houghton, "Antisense-mediated reduction in insulin-like growth factor-I receptor expression suppresses the malignant phenotype of a human alveolar rhabdomyosarcoma," Journal of Clinical Investigation, vol. 94, no. 3, pp. 1235-1242, 1994.

[60] K. Scotlandi, S. Avnet, S. Benini et al., "Expression of an IGF-I receptor dominant negative mutant induces apoptosis, inhibits tumorigenesis and enhances chemosensitivity in Ewing's sarcoma cells," International Journal of Cancer, vol. 101, no. 1, pp. 11-16, 2002.

[61] K. Scotlandi, S. Benini, P. Nanni et al., "Blockage of insulinlike growth factor-I receptor inhibits the growth of Ewing's sarcoma in athymic mice," Cancer Research, vol. 58, no. 18, pp. 4127-4131, 1998.

[62] E. Anders Kolb, R. Gorlick, P. J. Houghton et al., "Initial testing (stage 1) of a monoclonal antibody ( $\mathrm{SCH} 717454$ ) against the IGF-1 receptor by the pediatric preclinical testing program," Pediatric Blood and Cancer, vol. 50, no. 6, pp. 1190-1197, 2008.

[63] T. Kalebic, M. Tsokos, and L. J. Helman, "In vivo treatment with antibody against IGF-1 receptor suppresses growth of human rhabdomyosarcoma and down-regulates p34(cdc2)," Cancer Research, vol. 54, no. 21, pp. 5531-5534, 1994.

[64] K. Scotlandi, M. C. Manara, G. Nicoletti et al., "Antitumor activity of the insulin-like growth factor-I receptor kinase inhibitor NVP-AEW541 in musculoskeletal tumors," Cancer Research, vol. 65, no. 9, pp. 3868-3876, 2005.

[65] A. S. Martins, C. Mackintosh, D. Herrero Martín et al., "Insulin-like growth factor I receptor pathway inhibition by ADW742, alone or in combination with imatinib, doxorubicin, or vincristine, is a novel therapeutic approach in Ewing tumor," Clinical Cancer Research, vol. 12, no. 11 I, pp. 35323540, 2006.

[66] M. C. Manara, L. Landuzzi, P. Nanni et al., "Preclinical in vivo study of new insulin-like growth factor-I receptor-specific inhibitor in Ewing's sarcoma," Clinical Cancer Research, vol. 13, no. 4, pp. 1322-1330, 2007. 
[67] L. Cao, Y. Yu, I. Darko et al., "Addiction to elevated insulinlike growth factor I receptor and initial modulation of the AKT pathway define the responsiveness of rhabdomyosarcoma to the targeting antibody," Cancer Research, vol. 68, no. 19, pp. 8039-8048, 2008.

[68] A. W. Tolcher, J. Sarantopoulos, A. Patnaik et al., "Phase I, pharmacokinetic, and pharmacodynamic study of AMG 479, a fully human monoclonal antibody to insulin-like growth factor receptor 1," Journal of Clinical Oncology, vol. 27, no. 34, pp. 5800-5807, 2009.

[69] D. Olmos, S. Postel-Vinay, L. R. Molife et al., "Safety, pharmacokinetics, and preliminary activity of the anti-IGF$1 \mathrm{R}$ antibody figitumumab (CP-751,871) in patients with sarcoma and Ewing's sarcoma: a phase 1 expansion cohort study," The Lancet Oncology, vol. 11, no. 2, pp. 129-135, 2010.

[70] P. Schoffski, D. Adkins, J. Blay et al., "Phase II trial of antiIGF-IR antibody cixutumumab in patients with advanced or metastatic soft-tissue sarcoma and Ewing family of tumors," Journal of Clinical Oncology, vol. 29, abstract 10004, 2011.

[71] K. Scotlandi, M. C. Manara, G. Nicoletti et al., "Antitumor activity of the insulin-like growth factor-I receptor kinase inhibitor NVP-AEW541 in musculoskeletal tumors," Cancer Research, vol. 65, no. 9, pp. 3868-3876, 2005.

[72] A. S. Martins, C. Mackintosh, D. Herrero Martín et al., "Insulin-like growth factor I receptor pathway inhibition by ADW742, alone or in combination with imatinib, doxorubicin, or vincristine, is a novel therapeutic approach in Ewing tumor," Clinical Cancer Research, vol. 12, no. 11 I, pp. 35323540, 2006.

[73] M. C. Manara, L. Landuzzi, P. Nanni et al., "Preclinical in vivo study of new insulin-like growth factor-I receptor-specific inhibitor in Ewing's sarcoma," Clinical Cancer Research, vol. 13, no. 4, pp. 1322-1330, 2007.

[74] P. Sabbatini, J. L. Rowand, A. Groy et al., "Antitumor activity of GSK1904529A, a small-molecule inhibitor of the insulinlike growth factor-I receptor tyrosine kinase," Clinical Cancer Research, vol. 15, no. 9, pp. 3058-3067, 2009.

[75] P. Sabbatini, S. Korenchuk, J. L. Rowand et al., "GSK1838705A inhibits the insulin-like growth factor-1 receptor and anaplastic lymphoma kinase and shows antitumor activity in experimental models of human cancers," Molecular Cancer Therapeutics, vol. 8, no. 10, pp. 2811-2820, 2009.

[76] F. Huang, A. Greer, W. Hurlburt et al., "The mechanisms of differential sensitivity to an insulin-like growth factor-1 receptor inhibitor (BMS-536924) and rationale for combining with EGFR/HER2 inhibitors," Cancer Research, vol. 69, no. 1, pp. 161-170, 2009.

[77] N. Friedrichs, J. Küchler, E. Endl et al., "Insulin-like growth factor-1 receptor acts as a growth regulator in synovial sarcoma," Journal of Pathology, vol. 216, no. 4, pp. 428-439, 2008.

[78] Z. Duan, E. Choy, D. Harmon et al., "Insulin-like growth factor-I receptor tyrosine kinase inhibitor cyclolignan picropodophyllin inhibits proliferation and induces apoptosis in multidrug resistant osteosarcoma cell lines," Molecular Cancer Therapeutics, vol. 8, no. 8, pp. 2122-2130, 2009.

[79] X. Wan and L. J. Helman, "The biology behind mTOR inhibition in sarcoma," Oncologist, vol. 12, no. 8, pp. 10071018, 2007.

[80] A. A. Samani, S. Yakar, D. LeRoith, and P. Brodt, "The role of the IGF system in cancer growth and metastasis: overview and recent insights," Endocrine Reviews, vol. 28, no. 1, pp. 2047, 2007.
[81] Y. Xie, B. Skytting, G. Nilsson, B. Brodin, and O. Larsson, "Expression of insulin-like growth factor-1 receptor in synovial sarcoma: association with an aggressive phenotype," Cancer Research, vol. 59, no. 15, pp. 3588-3591, 1999.

[82] L. Girnita, A. Girnita, M. Wang, J. M. Meis-Kindblom, L. G. Kindblom, and O. Larsson, "A link between basic fibroblast growth factor (bFGF) and EWS/FLI-1 in Ewing's sarcoma cells," Oncogene, vol. 19, no. 37, pp. 4298-4301, 2000.

[83] D. P. M. Hughes, D. G. Thomas, T. J. Giordano, L. H. Baker, and K. T. McDonagh, "Cell surface expression of epidermal growth factor receptor and her-2 with nuclear expression of Her-4 in primary osteosarcoma," Cancer Research, vol. 64, no. 6, pp. 2047-2053, 2004.

[84] R. Ganti, S. X. Skapek, J. Zhang et al., "Expression and genomic status of EGFR and ErbB-2 in alveolar and embryonal rhabdomyosarcoma," Modern Pathology, vol. 19, no. 9, pp. 1213-1220, 2006.

[85] J. R. Sampson, "Therapeutic targeting of mTOR in tuberous sclerosis," Biochemical Society Transactions, vol. 37, no. 1, pp. 259-264, 2009.

[86] S. Umeoka, T. Koyama, Y. Miki, M. Akai, K. Tsutsui, and K. Togashi, "Pictorial review of tuberous sclerosis in various organs," Radiographics, vol. 28, no. 7, article e32, 2008.

[87] K. P. Boyd, B. R. Korf, and A. Theos, "Neurofibromatosis type 1," Journal of the American Academy of Dermatology, vol. 61, no. 1, pp. 1-14, 2009.

[88] D. Katz, A. Lazar, and D. Lev, "Malignant peripheral nerve sheath tumour (MPNST): the clinical implications of cellular signalling pathways," Expert Reviews in Molecular Medicine, vol. 11, p. e30, 2009.

[89] S. Mateo-Lozano, P. C. Gokhale, V. Soldatenkov, A. Dritschilo, O. M. Tirado, and V. Notario, "Combination therapy targeting EWS/FLI-1 oncogene induces apoptosis of Ewing's sarcoma cells in vitro and inhibits tumor growth in vivo," Clinical Cancer Research, vol. 12, pp. 6781-6790, 2006.

[90] P. J. Houghton, C. L. Morton, R. Gorlick et al., "Stage 2 combination testing of rapamycin with cytotoxic agents by the pediatric preclinical testing program," Molecular Cancer Therapeutics, vol. 9, no. 1, pp. 101-112, 2010.

[91] S. Schuetze, L. Zhao, and R. Chugh, "Results of a phase II trial of sirolimus (S) and cyclophosphamide (C) in advanced sarcoma ," Journal of Clinical Oncology, vol. 29, Abstract 10003, 2011.

[92] L. Dudkin, M. B. Dilling, P. J. Cheshire et al., "Biochemical correlates of mTOR inhibition by the rapamycin ester CCI779 and tumor growth inhibition," Clinical Cancer Research, vol. 7, no. 6, pp. 1758-1764, 2001.

[93] X. Wan, N. Shen, A. Mendoza, C. Khanna, and L. J. Helman, "CCI-779 inhibits rhabdomyosarcoma xenograft growth by an antiangiogenic mechanism linked to the targeting of mTOR/Hif-1 $\alpha$ /VEGF signaling," Neoplasia, vol. 8, no. 5, pp. 394-401, 2006.

[94] S. Okuno, H. Bailey, M. R. Mahoney et al., "A phase 2 study of temsirolimus (CCI-779) in patients with soft tissue sarcomas: a study of the mayo phase 2 Consortium (P2C)," Cancer, vol. 117, no. 15, pp. 3468-3475, 2011.

[95] B. Geoerger, M. W. Kieran, S. Grupp et al., "Phase II study of temsirolimus in children with high-grade glioma, neuroblastoma, and rhabdomyosarcoma," Journal of Clinical Oncology, vol. 28, no. 15S, abstract 9541, 2010.

[96] E. Hernando, E. Charytonowicz, M. E. Dudas et al., "The AKT-mTOR pathway plays a critical role in the development of leiomyosarcomas," Nature Medicine, vol. 13, no. 6, pp. 748-753, 2007. 
[97] S. Richter, D. Pink, P. Hohenberger et al., "Multicenter, triplearm, single-stage, phase II trial to determine the efficacy and safety of everolimus (RAD001) in patients with refractory bone or soft tissue sarcomas including GIST," Journal of Clinical Oncology, vol. 28, no. 15S, abstract 10038, 2010.

[98] R. M. Squillace, D. Miller, M. Cookson et al., "Antitumor activity of ridaforolimus and potential cell cycle determinants of sensitivity in sarcoma and endometrial cancer models," Molecular Cancer Therapeutics, vol. 10, pp. 1959-1968, 2011.

[99] S. P. Chawla, A. P. Staddon, L. H. Baker et al., "Phase II study of the mammalian target of rapamycin inhibitor ridaforolimus in patients with advanced bone and soft tissue sarcomas," Journal of Clinical Oncology, vol. 30, no. 1, pp. 7884, 2012.

[100] S. P. Chawla, J. Blay, I. L. Ray-Coquard et al., "Results of the phase III, placebo-controlled trial (SUCCEED) evaluating the mTOR inhibitor ridaforolimus (R) as maintenance therapy in advanced sarcoma patients (pts) following clinical benefit from prior standard cytotoxic chemotherapy (CT)," Annals of Oncology, vol. 29, abstract 10005, 2011.

[101] A. J. Wagner, I. Malinowska-Kolodziej, J. A. Morgan et al., "Clinical activity of mTOR inhibition with sirolimus in malignant perivascular epithelioid cell tumors: targeting the pathogenic activation of mTORC1 in tumors," Journal of Clinical Oncology, vol. 28, no. 5, pp. 835-840, 2010.

[102] A. Italiano, C. Delcambre, I. Hostein et al., "Treatment with the mTOR inhibitor temsirolimus in patients with malignant PEComa perivascular epithelioid cell tumors (PEComas) are rare," Annals of Oncology, vol. 21, no. 5, pp. 1135-1137, 2010.

[103] V. Subbiah, J. C. Trent, and R. Kurzrock, "Resistance to mammalian target of rapamycin inhibitor therapy in perivascular epithelioid cell tumors," Journal of Clinical Oncology, vol. 28, no. 24, p. e415, 2010.

[104] M. Sáinz-Jaspeado, J. Martin-Liberal, L. Lagares-Tena, S. Mateo-Lozano, X. Garcia-del-Muro, and O. M. Tirado, "Caveolin-1 in sarcomas: friend or foe?" Oncotarget, vol. 2, pp. 305-312, 2011.

[105] G. A. McArthur, G. D. Demetri, A. Van Oosterom et al., "Molecular and clinical analysis of locally advanced dermatofibrosarcoma protuberans treated with imatinib: imatinib target exploration consortium study B2225," Journal of Clinical Oncology, vol. 23, no. 4, pp. 866-873, 2005.

[106] P. Rutkowski, M. Van Glabbeke, C. J. Rankin et al., "Imatinib mesylate in advanced dermatofibrosarcoma protuberans: pooled analysis of two phase II clinical trials," Journal of Clinical Oncology, vol. 28, no. 10, pp. 1772-1779, 2010.

[107] J. D. G. Goldberg, E. Choy, L. Rosen et al., "Preliminary results from a phase II study of ARQ197 in patients with microphthalmia transcription family (MiT)-associated tumors," Journal of Clinical Oncology, vol. 27, abstract 10502, 2009.

[108] H. V. Erkizan, Y. Kong, M. Merchant et al., "A small molecule blocking oncogenic protein EWS-FLI1 interaction with RNA helicase A inhibits growth of Ewing's sarcoma," Nature Medicine, vol. 15, no. 7, pp. 750-756, 2009.

[109] C. J. Breitbach, J. Burke, D. Jonker et al., "Intravenous delivery of a multi-mechanistic cancer-targeted oncolytic poxvirus in humans," Nature, vol. 477, pp. 99-102, 2011.

[110] G. Li, H. Kawashima, A. Ogose et al., "Efficient virotherapy for osteosarcoma by telomerase-specific oncolytic adenovirus," Journal of Cancer Research and Clinical Oncology, vol. 137, no. 6, pp. 1037-1051, 2011.
[111] R. T. Kurmasheva, L. Dudkin, C. Billups, L. V. Debelenko, C. L. Morton, and P. J. Houghton, "The insulin-like growth factor-1 receptor-targeting antibody, CP-751,871, suppresses tumor-derived VEGF and synergizes with rapamycin in models of childhood sarcoma," Cancer Research, vol. 69, no. 19, pp. 7662-7671, 2009.

[112] F. Huang, A. Greer, W. Hurlburt et al., "The mechanisms of differential sensitivity to an insulin-like growth factor-1 receptor inhibitor (BMS-536924) and rationale for combining with EGFR/HER2 inhibitors," Cancer Research, vol. 69, no. 1, pp. 161-170, 2009.

[113] A. S. Martins, J. L. Ordoñez, A. García-Sánchez et al., "A pivotal role for heat shock protein 90 in Ewing sarcoma resistance to anti-insulin-like growth factor 1 receptor treatment: in vitro and in vivo study," Cancer Research, vol. 68, no. 15, pp. 6260-6270, 2008.

[114] R. Quek, Q. Wang, J. A. Morgan et al., "Combination mTOR and IGF-1R inhibition: phase I trial of everolimus and figitumumab in patients with advanced sarcomas and other solid tumors," Clinical Cancer Research, vol. 17, no. 4, pp. 871-879, 2011.

[115] A. Naing, R. Kurzrock, A. Burger et al., "Phase I trial of cixutumumab combined with temsirolimus in patients with advanced cancer," Clinical Cancer Research, vol. 17, pp. 60526060, 2011.

[116] J. E. Butrynski, D. R. D’Adamo, J. L. Hornick et al., "Crizotinib in ALK-rearranged inflammatory myofibroblastic tumor," New England Journal of Medicine, vol. 363, no. 18, pp. 1727-1733, 2010.

[117] A. Zibat, E. Missiaglia, A. Rosenberger et al., "Activation of the hedgehog pathway confers a poor prognosis in embryonal and fusion gene-negative alveolar rhabdomyosarcoma," Oncogene, vol. 29, no. 48, pp. 6323-6330, 2010.

[118] M. Hirotsu, T. Setoguchi, H. Sasaki et al., "Smoothened as a new therapeutic target for human osteosarcoma," Molecular Cancer, vol. 9, article 5, 2010.

[119] T. D. Tiet, S. Hopyan, P. Nadesan et al., "Constitutive Hedgehog signaling in chondrosarcoma up-regulates tumor cell proliferation," American Journal of Pathology, vol. 168, no. 1, pp. 321-330, 2006.

[120] J. Joo, L. Christensen, K. Warner et al., "GLI1 is a central mediator of EWS/FLI1 signaling in Ewing Tumors," PLoS ONE, vol. 4, no. 10, Article ID e7608, 2009.

[121] E. Beauchamp, G. Bulut, O. Abaan et al., "GLI1 is a direct transcriptional target of EWS-FLI1 oncoprotein," Journal of Biological Chemistry, vol. 284, no. 14, pp. 9074-9082, 2009.

[122] J. Roma, A. Masià, J. Reventós, J. S. De Toledo, and S. Gallego, "Notch pathway inhibition significantly reduces rhabdomyosarcoma invasiveness and mobility in vitro," Clinical Cancer Research, vol. 17, no. 3, pp. 505-513, 2011.

[123] M. Tanaka, T. Setoguchi, M. Hirotsu et al., "Inhibition of Notch pathway prevents osteosarcoma growth by cell cycle regulation," British Journal of Cancer, vol. 100, no. 12, pp. 1957-1965, 2009.

[124] E. R. Sampson, V. Amin, E. M. Schwarz, R. J. O'Keefe, and R. N. Rosier, "The histone deacetylase inhibitor vorinostat selectively sensitizes fibrosarcoma cells to chemotherapy," Journal of Orthopaedic Research, vol. 29, no. 4, pp. 623-632, 2011.

[125] L. Su, H. Cheng, A. V. Sampaio, T. O. Nielsen, and T. M. Underhill, "EGR1 reactivation by histone deacetylase inhibitors promotes synovial sarcoma cell death through 
the PTEN tumor suppressor," Oncogene, vol. 29, no. 30, pp. 4352-4361, 2010.

[126] A. Hrzenjak, F. Moinfar, M. L. Kremser et al., "Histone deacetylase inhibitor vorinostat suppresses the growth of uterine sarcomas in vitro and in vivo," Molecular Cancer, vol. 9, article 49, 2010.

[127] T. O. Nielsen, A. Nguyen, L. Su, B. Campbell, and N. M. Poulin, "Synergism of heat shock protein 90 and histone deacetylase inhibitors in synovial sarcoma," Sarcoma, vol. 2009, Article ID 794901, 2009.

[128] J. M. Lubieniecka, D. R. H. De Bruijn, L. Su et al., "Histone deacetylase inhibitors reverse SS18-SSX-mediated polycomb silencing of the tumor suppressor early growth response 1 in synovial sarcoma," Cancer Research, vol. 68, no. 11, pp. 43034310, 2008.

[129] M. C. Manara, G. Nicoletti, D. Zambelli et al., "NVP-BEZ235 as a new therapeutic option for sarcomas," Clinical Cancer Research, vol. 16, no. 2, pp. 530-540, 2010.

[130] C. R. Müller, E. B. Paulsen, P. Noordhuis, F. Pedeutour, G. Sæter, and O. Myklebost, "Potential for treatment of liposarcomas with the MDM2 antagonist Nutlin-3A," International Journal of Cancer, vol. 121, no. 1, pp. 199-205, 2007.

[131] M. S. Brassesco, M. A. Cortez, E. T. Valera et al., "Cryptic SYT/SXX1 fusion gene in high-grade biphasic synovial sarcoma with unique complex rearrangement and extensive BCL2 overexpression," Cancer Genetics and Cytogenetics, vol. 196, no. 2, pp. 189-193, 2010.

[132] O. M. Tirado, S. Mateo-Lozano, and V. Notario, "Roscovitine is an effective inducer of apoptosis of Ewing's sarcoma family tumor cells in vitro and in vivo," Cancer Research, vol. 65, no. 20, pp. 9320-9327, 2005. 


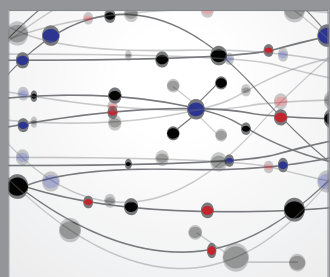

The Scientific World Journal
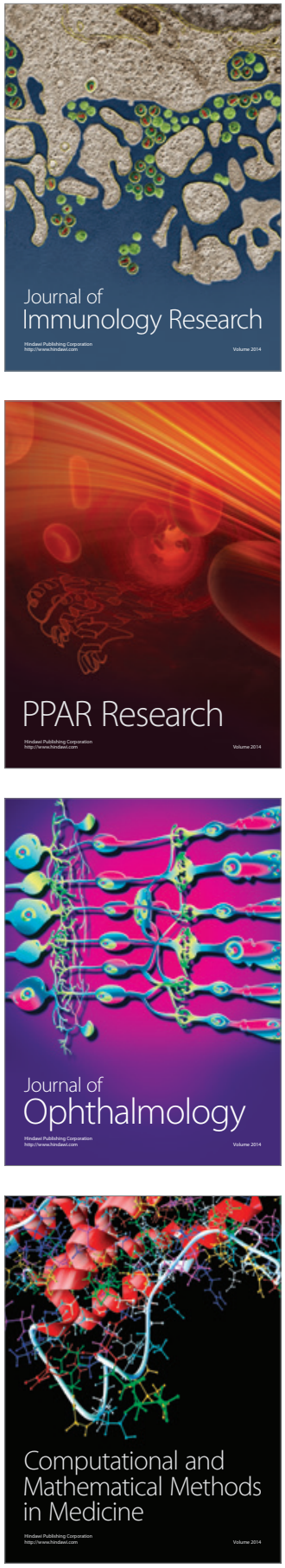

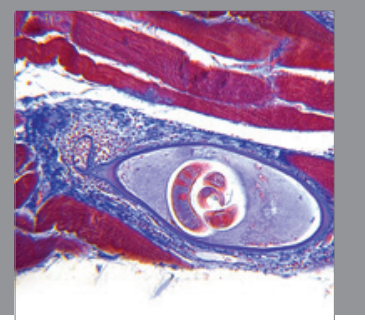

Gastroenterology

Research and Practice
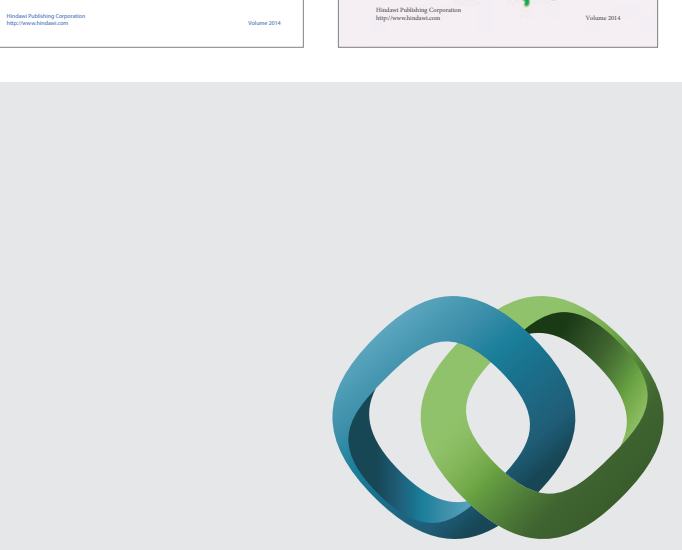

\section{Hindawi}

Submit your manuscripts at

http://www.hindawi.com
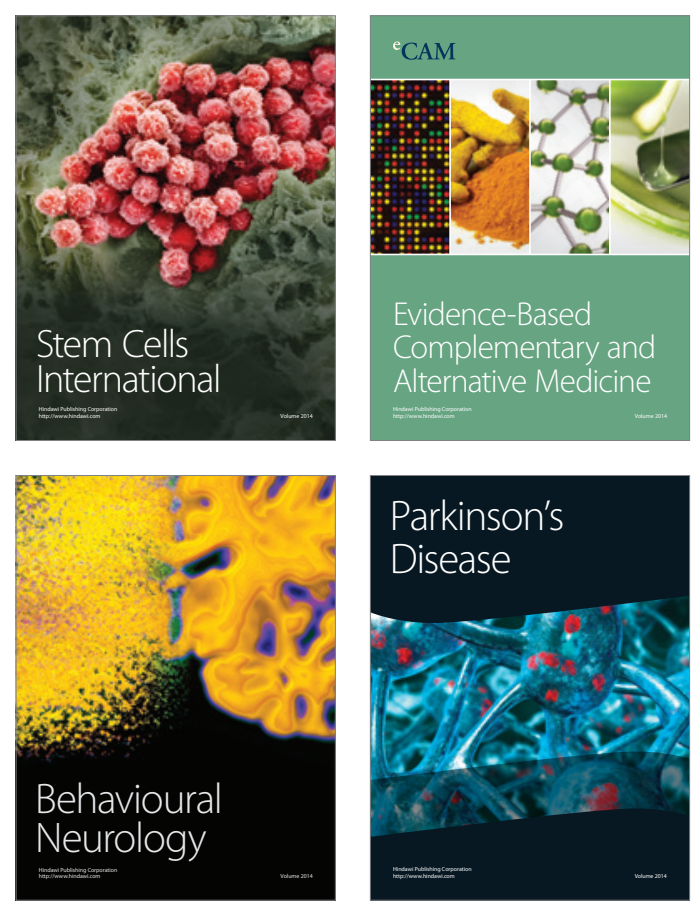

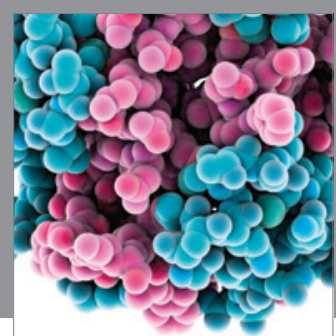

Journal of
Diabetes Research

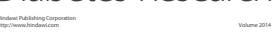

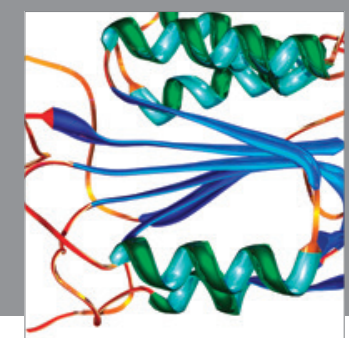

Disease Markers
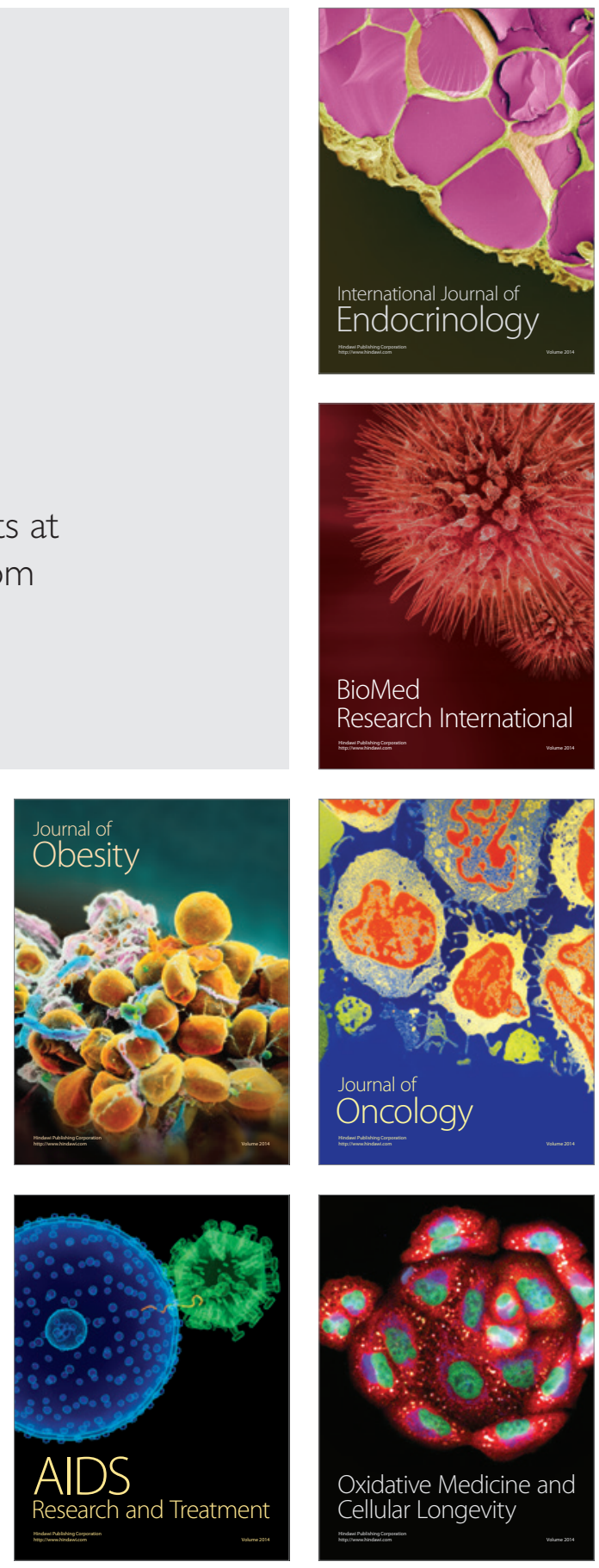